\title{
The roles of dynamical variability and aerosols in cirrus cloud formation
}

\author{
B. Kärcher ${ }^{1}$ and J. Ström ${ }^{2}$ \\ ${ }^{1}$ Deutsches Zentrum für Luft- und Raumfahrt (DLR), Institut für Physik der Atmosphäre, Oberpfaffenhofen, Germany \\ ${ }^{2}$ Stockholm University, Institute of Applied Environmental Research, Stockholm, Sweden
}

Received: 5 February 2003 - Published in Atmos. Chem. Phys. Discuss.: 14 March 2003

Revised: 17 June 2003 - Accepted: 17 June 2003 - Published: 23 June 2003

\begin{abstract}
The probability of occurrence of ice crystal number densities in young cirrus clouds is examined based on airborne measurements. The observations have been carried out at midlatitudes in both hemispheres at equivalent latitudes $\left(52-55^{\circ} \mathrm{N} / \mathrm{S}\right)$ during the same season (local autumn in 2000). The in situ measurements considered in the present study include temperatures, vertical velocities, and total ice crystal concentrations, the latter determined with high precision and accuracy using a counterflow virtual impactor. Most young cirrus clouds typically contain high number densities $\left(1-10 \mathrm{~cm}^{-3}\right.$ ) of small (diameter $<20 \mu \mathrm{m}$ ) ice crystals. This mode dominates the probability distributions and is shown to be caused by rapid cooling rates associated with updraft speeds in the range $10-100 \mathrm{~cm} \mathrm{~s}^{-1}$. A second mode containing larger crystals extends from $\sim 1 \mathrm{~cm}^{-3}$ to low concentrations close to the detection threshold $\left(\sim 3 \times 10^{-4} \mathrm{~cm}^{-3}\right)$ and could be associated with lower updraft speeds. Results of a statistical analysis provide compelling evidence that the dynamical variability of vertical air motions on the mesoscale is the key factor determining the observed probability distributions of pristine ice crystal concentrations in cirrus. Other factors considered are changes of temperature as well as size, number, and ice nucleation thresholds of the freezing aerosol particles. The variability in vertical velocities is caused by atmospheric gravity waves leading to small-scale temperature fluctuations. Inasmuch as gravity waves are widespread, mesoscale variability in vertical velocities can be viewed as a universal feature of young cirrus clouds. Large-scale models that do not account for this subgrid-scale variability yield erroneous predictions of the variability of basic cirrus cloud properties. Climate change may bring about changes in the global distribution of updraft speeds, mean air temperatures, and aerosol properties. As shown in this work, these changes could significantly modify the probability distribution of cirrus ice crystal concentrations. This study emphasizes the key
\end{abstract}

Correspondence to: B. Kärcher (bernd.kaercher@ dlr.de) role of vertical velocities and mesoscale variability in vertical velocities in controlling cirrus properties. The results suggest that, in any effort to ascribe cause to trends of cirrus cloud properties, a careful evaluation of dynamical changes in cloud formation should be done before conclusions regarding the role of other anthropogenic factors, such as changes in aerosol composition, are made.

\section{Introduction}

It has long been recognized that dynamical processes influence the characteristic, heterogeneous macrostructure of cirrus clouds. Relevant dynamical processes in the upper troposphere and tropopause region include mesoscale gravity waves (e.g. arising from convection or from synoptic-scale weather systems operating over a wide range of scales between a few and many tens of kilometers); lee waves generated downwind of mountain ridges; background air turbulence as a result of shear generation (e.g. near the jet stream); and intrinsic turbulence generated by latent heat and radiative processes within cloud. Turbulence and wave activity often appear as coupled phenomena and cannot easily be separated. Model studies highlighted the complex suite of interactions between radiative, microphysical, and dynamical processes in cirrus clouds (Starr and Cox, 1985; Zhang et al., 1992). Knowledge of dynamical factors influencing both, cirrus cloud macrophysical properties and microphysical structure is required to assess the radiative effects of cirrus and hence their role in climate (Stephens et al., 1990; Quante and Starr, 2002).

Comparatively little emphasis has been put on the role dynamical processes play during the formation of cirrus clouds, although the processes affecting cloud formation may influence the entire life cycle of the cloud. An early field study revealed that ice crystal properties in cirrus clouds are strong functions of the vertical velocity $w$ and temperature

(C) European Geosciences Union 2003 
$T$ (Heymsfield, 1977). The potential impact of atmospheric waves on the physical properties of young cirrus clouds, in particular on the number concentration $n_{i}$ of small (diameter below $20 \mu \mathrm{m}$ ) ice crystals, was demonstrated in airborne measurements (Ström etal., 1997). Orographic effects on cirrus were reported in field studies (Heymsfield and Miloshevich, 1993). The importance of mountain waves for the generation of polar stratospheric (ice) clouds in the Arctic is well recognized (Carslaw et al., 1998).

Most parcel models used a simplified dynamical setup with constant cooling rates to study the initiation of the ice phase in detail (Lin etal., 2002). One model study pointed out the essential role of scale-dependent vertical wind fields on ice crystal concentration and other cloud parameters (Jensen et al., 1994). Another study investigated the influence of waves on cirrus formed by homogeneous freezing (Lin et al., 1998). A parameterization scheme describing the formation of cirrus clouds was derived from basic physical principles (Kärcher and Lohmann, 2002, 2003), connecting $n_{i}$ with the variables $w$ and $T$ describing the dynamical cloud forcing, and with parameters of the freezing aerosol particles establishing the microphysical link. Simulations of cirrus clouds in a general circulation model (based on the parameterization) called for the need to better represent subgrid scale variability of vertical motions to predict cloud properties (Lohmann and Kärcher, 2002), a crucial aspect we elucidate further in the present study.

The role aerosol particles from natural and anthropogenic sources play in cirrus cloud formation is not yet adequately understood. The possible aerosol impact on cloud properties is difficult to quantify. Concerns were raised about potential modifications of cirrus clouds by aircraft particle emissions and contrails (Boucher, 1999; IPCC, 1999). One model study demonstrated that carbonaceous aerosol particles exhausted by aircraft jet engines, when assumed to act as efficient ice nuclei in weak updrafts, could expand cirrus cover and change physical and optical cloud properties (Jensen and Toon, 1997). However, systematic studies aimed at assessing the role of aerosols in cirrus modification that cover a wider range of dynamical forcings - a point we are addressing in more detail in this work - are not available.

In the present study, we gain insight into basic properties and formation mechanisms of upper tropospheric cirrus from examining the probability distributions of measured total ice crystal number densities. The aforementioned parameterization is employed to study the relative importance of dynamical factors and properties of the freezing aerosol for cirrus formation. The calculations are mostly based on wind, temperature, and aerosol data gathered during the INCA (Interhemispheric Differences in Cirrus Properties From Anthropogenic Emissions) campaign and are compared with ice crystal concentrations measured simultaneously. We focus on cirrus forming in situ and do not address the generation of cirrus by convective detrainment of cloud condensate.

\section{INCA Experiment}

During the INCA experiment, the DLR (Deutsches Zentrum für Luft- und Raumfahrt) research aircraft Falcon was operated out of Punta Arenas, Chile, in the southern hemisphere (SH) campaign and out of Prestwick, Scotland, in the nothern hemisphere $(\mathrm{NH})$ campaign. The campaigns comprised $30-40$ flight hours each in autumn and employed an identical set of instruments to measure meteorological variables and radiative, chemical, and microphysical properties of aerosol and cirrus cloud particles. Throughout this work, we use the abbreviations $\mathrm{NH}$ and $\mathrm{SH}$ to distinguish between the two data sets.

We investigate measurements taken at air temperatures below $235 \mathrm{~K}$ to focus on pure ice clouds. Most flight patterns were designed to probe young cirrus clouds and their formation regions in upper cloud layers. Typically, the Falcon climbed to high altitudes above the top of any cirrus present. Very often, being clearly above the main cloud layer, the aircraft flew in a veil of patchy cirrus. The aircraft then descended into the main cloud layer. Several flight legs at different levels of $10-15$ min duration were flown within cloud. The flights ended by climbing to the stratosphere or cloud top altitude and then starting a stacked downward flight with levels of only $3-5$ min duration. An overview of the INCA experiment and the instruments deployed is available elsewhere (Gayet et al., 2002; Seifert et al., 2002).

\subsection{Temperatures and vertical velocities}

The Falcon temperature measurements were made with a Rosemount total temperature probe located underneath the nose of the aircraft. Airflow approaching the housing and the sensor in flight generates a dynamical heating due to flow stagnation. This heating must be accounted for using the pressure measurements of the airflow system to obtain the desired static air temperature $T$, constituting the major source of error in the temperature measurements. The uncertainty of $T$ is better than $\pm 0.5 \mathrm{~K}$.

The vertical wind component was deduced by substracting the vertical component of aircraft motion relative to the ground and the vertical component of aircraft motion relative to the surrounding air. The latter is measured with a 5hole-probe system with a relative precision (random noise) $<3 \mathrm{~cm} \mathrm{~s}^{-1}$ and a probable bias $\sim 20 \mathrm{~cm} \mathrm{~s}^{-1}$. The bias may be an unknown function of airspeed and air density an hence vary between different flight segments at different altitudes, while being almost constant during straight flight at constant speed. The vertical aircraft speed was determined by differentiation of the measured pressure using the hydrostatic equation. Therefore its absolute accuracy is limited by the equivalency of vertical aircraft motion and horizontal pressure gradients. This leads to typical biases of the order $10 \mathrm{~cm} \mathrm{~s}^{-1}$ (corresponding to an assumed horizontal gradient of $2 \mathrm{kPa}$ per $1000 \mathrm{~km}$ ). To reduce random noise to levels 

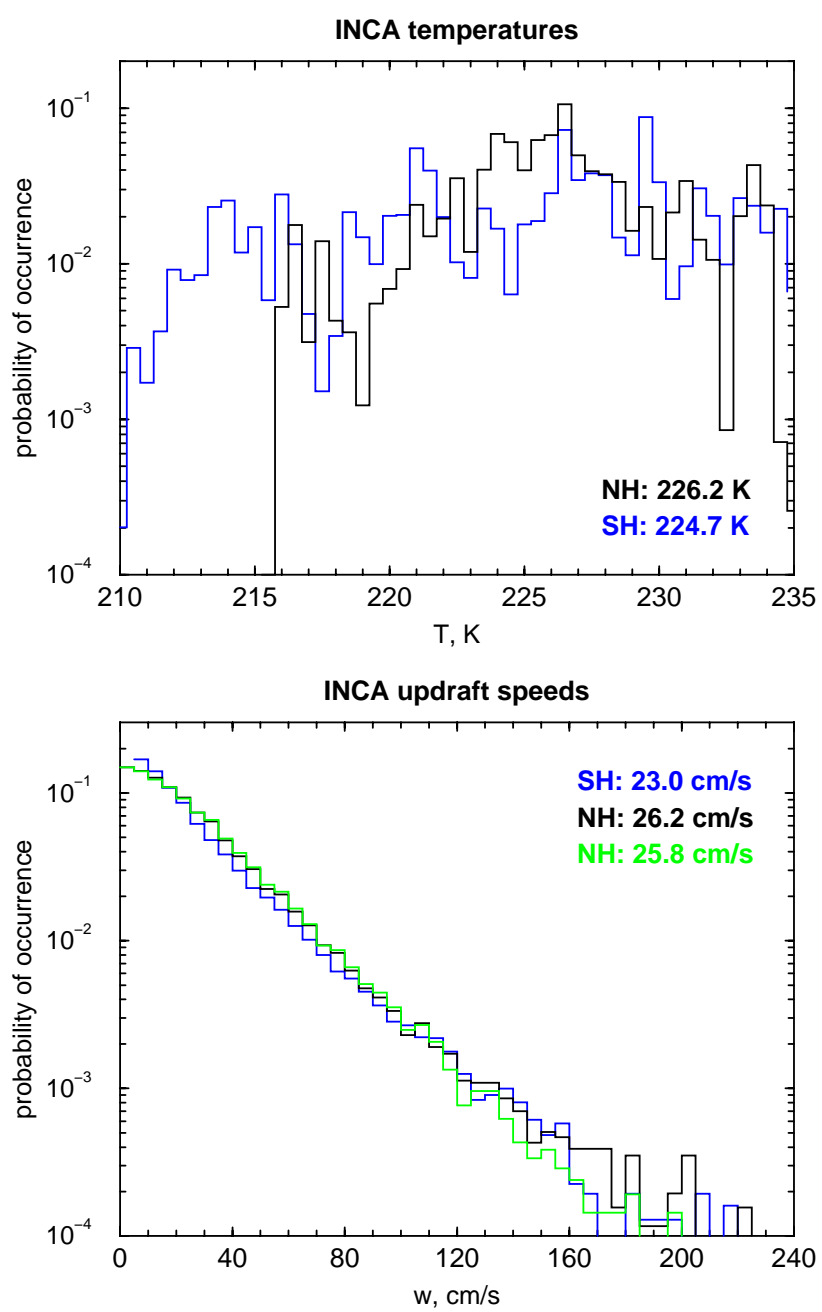

Fig. 1. Distributions of static air temperature $T$ (top) and upwind vertical velocity $w$ (bottom) derived from the Prestwick data set (NH, black distributions) and the Punta Arenas data set ( $\mathrm{SH}$, blue distributions). Mean values are indicated. The data sets represent all values measured below $235 \mathrm{~K}$. To produce the green distribution of $w$, we have removed all NH measurements associated with rapid vertical transport and convective influence (see text for details). Temperatures and vertical wind speeds were binned into $0.5 \mathrm{~K}$ and $5 \mathrm{~cm} \mathrm{~s}^{-1}$ intervals, respectively.

comparable to that of the airflow measurement, the output was filtered with a cut-off frequency of $0.1 \mathrm{~Hz}$. In summary, a bias error of $\pm 30 \mathrm{~cm} \mathrm{~s}^{-1}$ and a random noise of less than $\pm 5 \mathrm{~cm} \mathrm{~s}^{-1}$ can be assumed. More details of the calibration of the Falcon wind measurement system are discussed elsewhere (Bögel and Baumann, 1991).

The measured magnitude of $w$ depends on the horizontal scale probed by the aircraft. Vertical motions of the order of a few $\mathrm{cm} \mathrm{s}^{-1}$ may be associated with synoptic scale uplifts (scale $100 \mathrm{~km}$ or more). Vertical winds with a few $\mathrm{m} \mathrm{s}^{-1}$ are associated with isolated convective cells (scale of the order of $1 \mathrm{~km}$ ). Intermediate mesoscale gravity wave structures with wavelengths $\lambda$ of several tens of $\mathrm{km}$ are associated with velocity amplitudes of several tens of $\mathrm{cm} \mathrm{s}^{-1}$. The variances of the $w$ distributions ( $\sim 25 \mathrm{~cm} \mathrm{~s}^{-1}$, see below) thus indicate the prevalence of mesoscale variability during the cirrus measurements in both campaigns. Note that mesoscale wave motion can occasionally lead to updrafts in excess of $1 \mathrm{~m} \mathrm{~s}^{-1}$ and less than $1 \mathrm{~cm} \mathrm{~s}^{-1}$, indicating that a clear distinction between synoptic, mesoscale, and convective forcings cannot always be made.

The limited precision of the $w$ measurements $\left( \pm 5 \mathrm{~cm} \mathrm{~s}^{-1}\right.$, see above) implies that slow uplifts are not very well represented in the data sets, although they comprise a significant number of measurements. As the $w$ data have been taken at $1 \mathrm{~Hz}$ resolution but do not carry information above $0.1 \mathrm{~Hz}$ due to filtering, fluctuations of $w$ on scales below $1.8 \mathrm{~km}$ are not resolved, assuming a typical true airspeed of $180 \mathrm{~m} \mathrm{~s}^{-1}$.

Figure 1 depicts the probability of occurrence of temperature (top) and updraft velocity (bottom) measured during INCA, separated into NH (black distributions) and SH (blue distributions) data sets. The underlying data sets comprise all individual measurements made below $235 \mathrm{~K}$. We note that there are no significant differences between the distributions taken inside cloud and the corresponding ones containing all data points. The data sets comprising updraft and downdraft regions are nearly symmetrical (not shown), peaking at $-0.5 \mathrm{~cm} \mathrm{~s}^{-1}(\mathrm{NH})$ and $-3.9 \mathrm{~cm} \mathrm{~s}^{-1}(\mathrm{SH})$, hence, within the precision of the instrument. This indicates that there is no significant bias in the overall distributions shown in Fig. 1.

The campaign averages of $T$ and $w$ are given in Fig. 1. While mean temperatures are near $225 \mathrm{~K}$ in both cases, a few more data points below $215 \mathrm{~K}$ exist in the $\mathrm{SH}$ data set. The $\mathrm{NH}$ data set contains a larger number of updraft speeds above $\sim 100 \mathrm{~cm} \mathrm{~s}^{-1}$ than the SH data set, consistent with occasional convective activity observed during the NH campaign, but not in the SH. The statistics becomes very poor for values $w>160 \mathrm{~cm} \mathrm{~s}^{-1}$. There is only a slight difference of $3.2 \mathrm{~cm} \mathrm{~s}^{-1}$ between the mean $\mathrm{SH}$ and $\mathrm{NH}$ values.

It is not possible to infer sources of the variability in vertical velocities from the measurements, however, wave structures were at times evident in the cloud fields. Likely candidates for gravity waves are orographic forcings induced by the mountain ridges in Scotland and Chile, and perhaps shear-induced turbulence created near the jet stream during both campaigns. Lee wave activity at both locations could potentially explain the similarity seen in the vertical wind fields at both locations. We return to this issue in Sect. 4.1.

The green distribution of $w$ shown in Fig. 1 (bottom) is generated from a modified $\mathrm{NH}$ data set, where most of the measurements associated with pollution plumes that entered the upper troposphere via rapid vertical transport towards the end of the campaign have been removed. The polluted events were characterized by enhanced concentrations of carbon monoxide ( $\mathrm{CO}$ ) and reactive nitrogen, enhanced levels of turbulence, and increased frequency of occurrence of cumulus clouds. Such events have not been observed in the $\mathrm{SH}$ 
Table 1. Size distribution parameters of aerosol particles measured during INCA. The measurements are fitted to superimposed lognormal modes. Given are the campaign averages of the total number $n$, mean number diameter $D$, and geometrical width $\sigma$ for each individual mode from the northern $(\mathrm{NH})$ and southern hemisphere $(\mathrm{SH})$ measurements; $\mathrm{NH}$ (no convection) is based on the $\mathrm{NH}$ data set cleared of pollution events associated with convection.

\begin{tabular}{c|cccc}
\hline $\mathrm{SH}$ & & & & \\
$n\left[\mathrm{~cm}^{-3}\right]$ & 110 & 40 & - & 0.06 \\
$D[\mu \mathrm{m}]$ & 0.021 & 0.084 & - & 0.7 \\
$\sigma$ & 1.4 & 1.8 & - & 1.7 \\
\hline $\mathrm{NH}$ & & & & \\
$n\left[\mathrm{~cm}^{-3}\right]$ & 300 & 70 & 20 & 0.07 \\
$D[\mu \mathrm{m}]$ & 0.018 & 0.05 & 0.14 & 0.7 \\
$\sigma$ & 1.5 & 1.6 & 1.5 & 1.8 \\
\hline $\mathrm{NH}($ no convection) & & & & \\
$n\left[\mathrm{~cm}^{-3}\right]$ & 200 & 50 & 40 & 0.07 \\
$D[\mu \mathrm{m}]$ & 0.014 & 0.03 & 0.1 & 0.7 \\
$\sigma$ & 1.4 & 1.5 & 1.65 & 1.7 \\
\hline
\end{tabular}

campaign. The $\mathrm{NH}$ average $\mathrm{CO}$ volume mixing ratio in the upper troposphere was near $70 \mathrm{ppb}$ (Baehr et al., 2003). The green distribution was obtained by excluding all data points with $\mathrm{CO}$ mixing ratios $>90 \mathrm{ppb}$. While the distribution below $\sim 100 \mathrm{~cm} \mathrm{~s}^{-1}$ is almost unaffected, the impact of convective activity originally seen at higher vertical wind speeds is significantly reduced; the mean value of $w$ decreases only slightly by $0.4 \mathrm{~cm} \mathrm{~s}^{-1}$.

In summary, the distributions of $w$ (and $T$ ) were remarkably similar in both hemispheres during the INCA campaigns, especially when the influence of convection is removed from the NH measurements. The similarity of the vertical wind distributions may be coincidental; based on general circulation patterns and differences in the land/sea distributions, there should be significant differences in updraft speeds and cooling rates between the two hemispheres. In fact, measurement location and timing were chosen to minimize differences in meteorological conditions in order to focus on possible cirrus cloud modification induced by different aerosol properties.

\subsection{Aerosol particle size distributions}

We present the average aerosol size and number parameters derived from the measurements in Table 1. The parameters refer to multimodal lognormal functions that were used to fit the measured size distributions. The model described in Sect. 3.1 assumes that the freezing aerosol particles are lognormally distributed and employs these parameters. More details about observations of aerosol particles during INCA are discussed by Minikin et al. (2003).
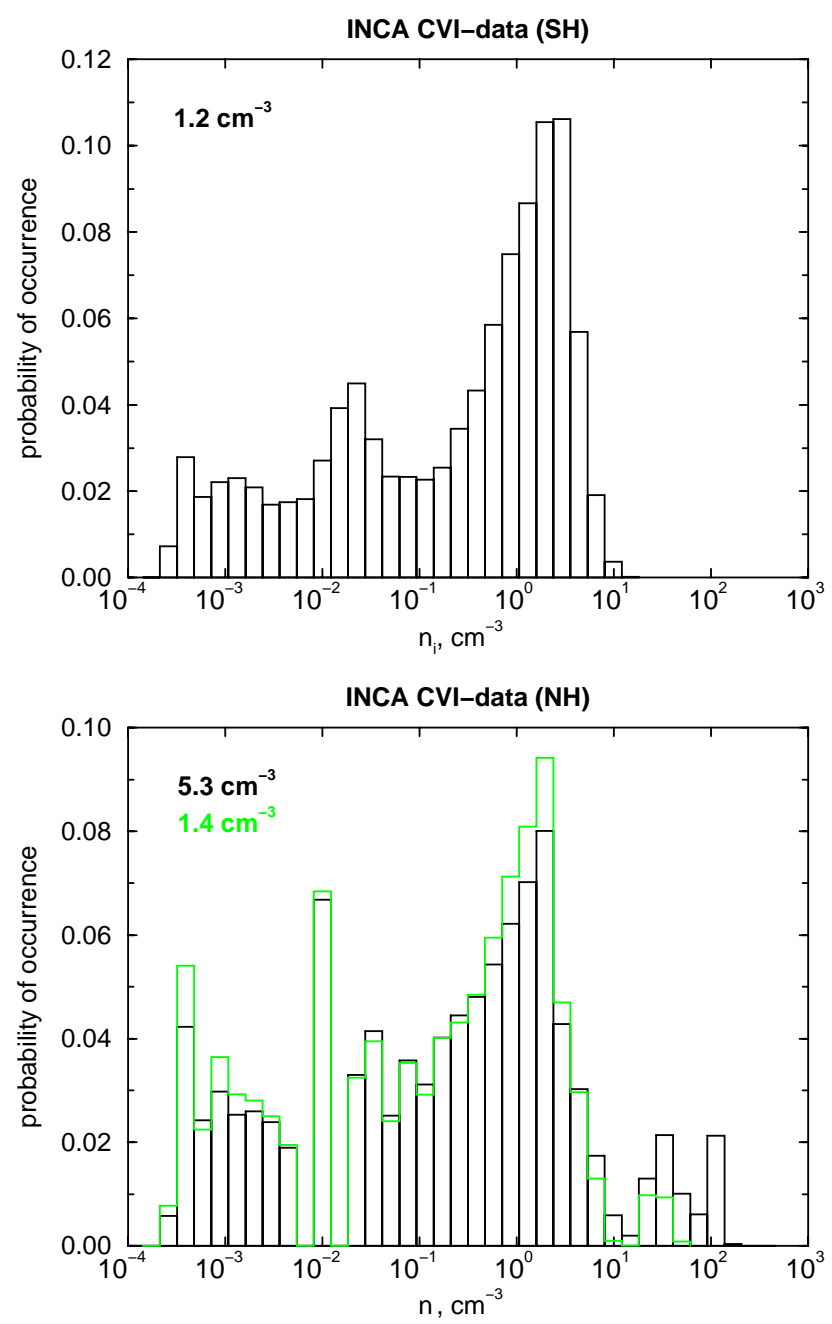

Fig. 2. Distributions (black histograms) of number densities $n_{i}$ of ice crystals for the Punta Arenas data set (SH, top) and the Prestwick data set ( $\mathrm{NH}$, bottom). The underlying data sets represent measurements inside cloud below $235 \mathrm{~K}$. Measurements in strongly polluted air masses affected by rapid vertical transport and convection are removed in the green distribution shown in the bottom panel. Mean values of $n_{i}$ are indicated. A logarithmic concentration grid was used and number densities were binned into constant $\Delta n_{i} / n_{i}=0.4$ intervals (sucessive bin center values $n_{i}$ increase by a factor of 1.5).

\subsection{Ice crystal concentrations}

To generate distribution functions for the total number density $n_{i}$ of cirrus ice crystals, we used all measurements where the counterflow virtual impactor (CVI) counted ice particles (i.e., $n_{i}>0$ ) and where the temperature was below the approximate spontaneous freezing limit of pure water drops $(T<235 \mathrm{~K})$. Figure 2 depicts the distribution functions of ice crystal concentrations taken by the CVI as black histograms. The CVI counts the residual particles remaining from evaporating cirrus ice crystals and assumes a oneto-one relation between the residual particle and ice crystal 
number density (Noone et al, 1988; Ström et al., 1997). This assumption is based on a careful intercomparison of several independent cloud probes deployed during INCA (Gayet et al., 2002; Seifert et al., 2002). For number densities above $\sim 1 \mathrm{~cm}^{-3}$, the CVI tends to underestimate the ice crystal concentrations. The reason is most likely that at these concentrations, some very small crystals are present with sizes below or close to the lower cut-off of the CVI, which is around $5 \mu \mathrm{m}$ in aerodynamic diameter. The lower detection limit in terms of number concentrations is $\sim 3 \times 10^{-4} \mathrm{~cm}^{-3}$. Within these limitations, we point out that the CVI data discussed here represent the total number density of cloud particles. Other cloud probes characterized by larger cut-off sizes and higher detection limits will count only smaller subsets of clouds particles.

On average, higher ice crystal number densities have been observed in the $\mathrm{NH}$ than in the $\mathrm{SH}$, compare the black distributions in Fig. 2. The distributions of $n_{i}$ taken in both hemispheres exhibit a similar shape, with a broad feature extending from $n_{i} \simeq 0.1 \mathrm{~cm}^{-3}$ down to the smallest concentrations, and a pronounced primary maximum in the concentration range $0.1-10 \mathrm{~cm}^{-3}$. Both distributions also show a secondary maximum at $\sim 0.02 \mathrm{~cm}^{-3}$. The observations of high numbers of relatively small ice crystals in the primary peak regions shown in Fig. 2 is believed to be a robust result (Gayet et al., 2002; Seifert et al., 2002). In the NH (SH), the broad feature contains $43 \%$ (39\%) and the primary peak region contains $50 \%$ (61\%) of the data, respectively. In the $\mathrm{NH}$ data set, $7 \%$ of the measurements indicate very high number densities of up to $200 \mathrm{~cm}^{-3}$.

The SH distribution and the $\mathrm{NH}$ distribution cleared of convective episodes are strikingly similar, compare the black SH histogram with the green NH stair steps in Fig. 2. The corresponding mean ice crystal concentrations are virtually identical. Given the fact that the dynamical forcings are nearly identical in both data sets (see Fig. 1), we begin to suspect that the actual properties of the freezing aerosol particles do not strongly affect the number distribution of ice crystals in cirrus. We will discuss this issue further in Sect. 4.

\section{Results}

\subsection{Methodology}

We connect the observed values of $n_{i}$ and $w, T$, aerosol size distribution parameters, and freezing threshold relative humidities RHI $_{\text {cr }}$ using a parameterization scheme for homogeneous and heterogeneous freezing nucleation (Kärcher and Lohmann, 2002, 2003). This scheme has been shown to reproduce initial ice particle concentrations simulated with a numerical parcel model within about a factor of two. The physical processes upon which the parameterization is based are essentially similar to those considered in detailed numerical simulations of the microphysics of ice initiation in cirrus, see Lin et al. (2002) for an overview. The values $n_{i}$ are calculated using the individual measurements of $w$ and $T$, not the binned distributions shown in Fig. 1.

In the calculations, we consider freezing of one single, chemically uniform aerosol type. Homogeneous freezing is assumed for the SH data set. Homogeneous freezing thresholds are known functions of $T$ and are of the order $155 \%$ for the mean air temperatures of interest (Koop et al., 2000). Heterogeneous freezing is assumed for the $\mathrm{NH}$ data set, with a nominal value $\mathrm{RHI}_{\mathrm{cr}}=130 \%$. Both choices for $\mathrm{RHI}_{\mathrm{cr}}$ are motivated by, and consistent with, analyses of relative humidities (Ström et al., 2003; Haag et al., 2003b) measured during INCA (Ovarlez et al., 2002). The freezing aerosol size distribution parameters are noted in Table 1.

It is not known which combinations of $w$ and $T$ can be attributed to cloud formation events. It is therefore not meaningful to study the distribution of $n_{i}$ for all possible combinations of $w$ and $T$, as this would lead to a uniform distribution of $n_{i}$. Also, not all signatures of small-scale dynamical activity may be captured by the distributions of $w$ employed here. However, it is meaningful to perform a statistical analysis of the measurements: varying one parameter and keeping the others fixed at their average (most probable) values allows to examine separately the sensitivity of the calculated concentration spectrum of ice crystals on the variability of aerosol parameters, temperatures, and updraft speeds.

\subsection{SH data}

The left column in Fig. 3 shows the results obtained with the SH data set. In Fig. 3a, $T$ was set to the mean value $224.7 \mathrm{~K}$, $w$ was set equal to the mean value $23 \mathrm{~cm} \mathrm{~s}^{-1}$, and aerosol parameters $n, D$, and $\sigma$ were varied around average values (see below). In Fig. 3b, aerosol parameters and $w$ were fixed, the employed distribution function of $T$ is depicted in Fig. 1. In Fig. 3c, aerosol parameters and $T$ were fixed, the employed distribution function of $w$ is depicted in Fig. 1.

Aerosol variability. To produce the green distribution in Fig. 3a, the average aerosol parameters noted in Table 1 have been varied within the ranges $\{0.2 n, 2.5 n\},\{0.2 D, 2.5 D\}$, and $\{0.8 \sigma, 1.25 \sigma\}$ for all modes; 50000 randomly distributed combinations of the 9 parameters have been generated. With these variations we likely overestimate the actual aerosol variability.

Figure $3 \mathrm{a}$ demonstrates that the variability introduced by rather large changes of the aerosol spectral paramaters produces an extremely narrow spectrum of ice crystal number densities, with a mean value of $0.5 \mathrm{~cm}^{-3}$. This relative insensitivity is expected on the basis of theoretical considerations, if only one type of freezing aerosol is present (Kärcher and Lohmann, 2002, 2003).

Temperature variability. To produce the green distribution in Fig. 3b, 59444 ice crystal concentrations have been computed based on the observed temperatures. The spectrum of $n_{i}$ shows some spread in the range $0.2-2 \mathrm{~cm}^{-3}$, 

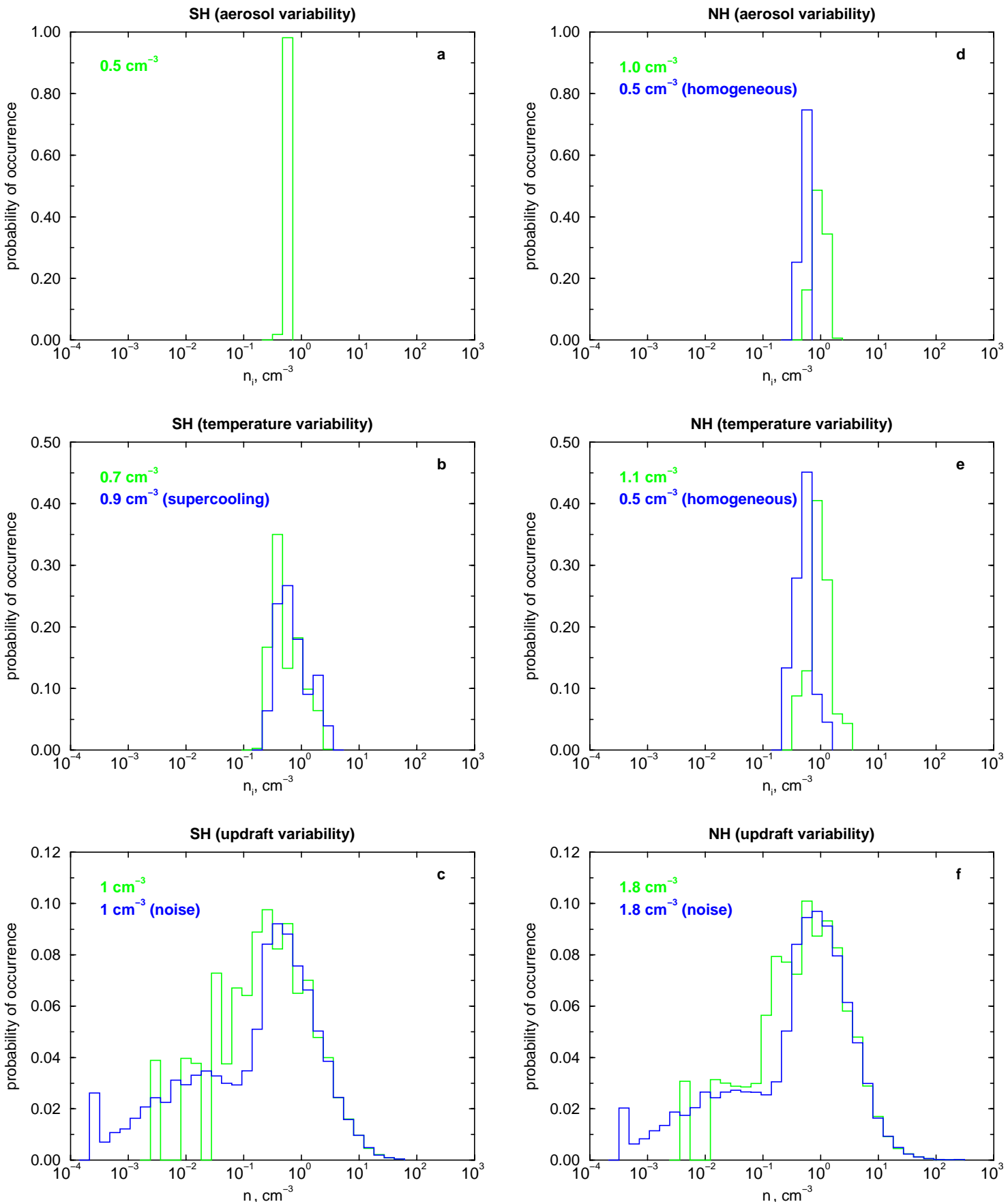

Fig. 3. Calculated distribution functions of ice particle number densities for the SH (a-c) and the NH (d-f). Mean values of $n_{i}$ are indicated. See text for details.

with a mean value of $0.7 \mathrm{~cm}^{-3}$. To produce the blue distribution, the same calculation has been carried out, but each temperature was lowered by $3 \mathrm{~K}$ (a supercooling consistent with homogeneous freezing) accounting for the fact that the ice-supersaturated regions within which the probed clouds formed were actually colder than the cloud-free environment. As a result, supercooling causes the distribution of $n_{i}$ to shift slightly towards higher concentrations (mean value $0.9 \mathrm{~cm}^{-3}$ ). The variance of $n_{i}$ remains much smaller than observed in both cases.

Updraft variability. To produce the green distribution in Fig. 3c, 31059 ice crystal concentrations have been computed based on the observed updraft speeds. The spectrum of $n_{i}$ is much broader than in the other cases, bracketing the 

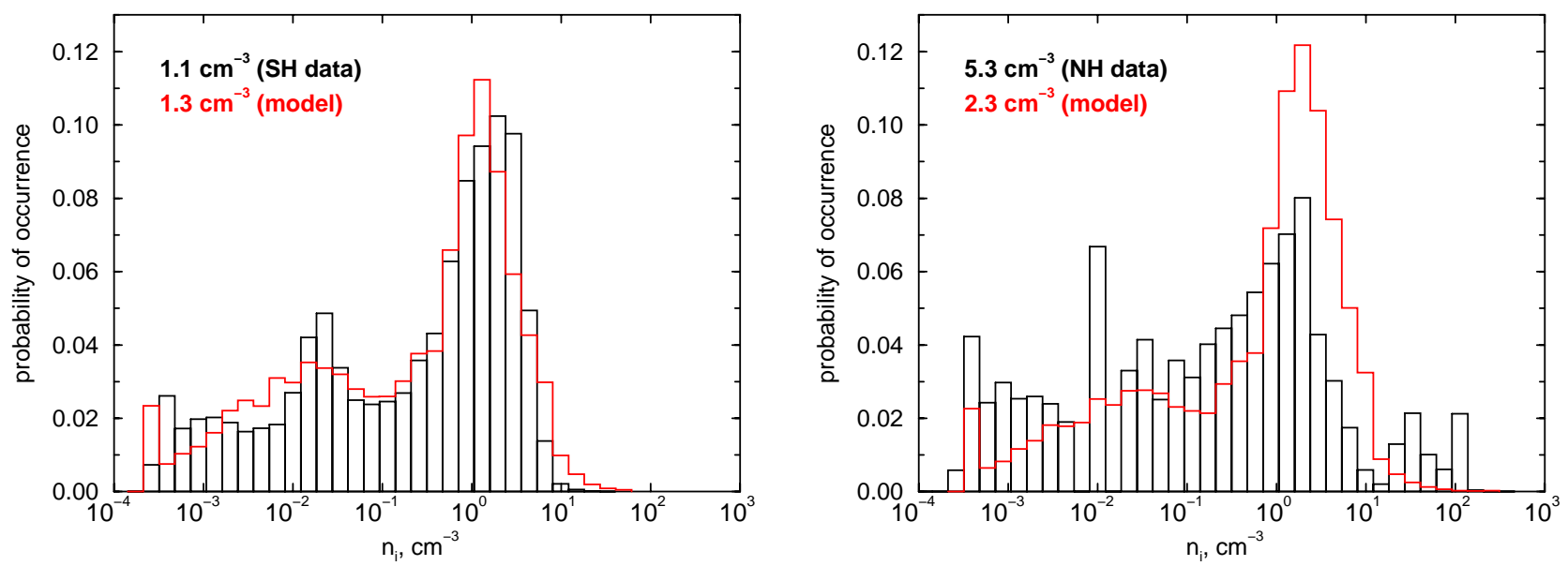

Fig. 4. Calculated (red stair steps) and observed (black histograms, taken from Fig. 2) distribution functions of ice particle number densities for the SH (left) and the NH (right). Mean values of $n_{i}$ are indicated. The modeled distributions account for mesoscale wave-driven variability (in the range $10-100 \mathrm{~cm} \mathrm{~s}^{-1}$ ) and noise $\left( \pm 5 \mathrm{~cm} \mathrm{~s}^{-1}\right.$ ) in the vertical velocity data and are calculated at average temperatures using average aerosol parameters. See text for details.

range $3 \times 10^{-3}-40 \mathrm{~cm}^{-3}$, with a mean value of $1 \mathrm{~cm}^{-3}$. In this case, a pronounced peak region develops in the concentration range $0.1-5 \mathrm{~cm}^{-3}$, as seen in the observations (top panel in Fig. 2).

Recall that the precision of the vertical velocity measurements is $\pm 5 \mathrm{~cm} \mathrm{~s}^{-1}$. This implies that the low velocity portion of the distribution shown in Fig. 1 is inaccurate in a range where most of the measurements have been taken, while the mid and high velocity ranges are largely unaffected. To account for these effects, the vertical velocities were randomized in the region below $10 \mathrm{~cm} \mathrm{~s}^{-1}$,

$$
w \longrightarrow \max \left\{0.2 \mathrm{~cm} \mathrm{~s}^{-1}, \operatorname{RAN}(0,1) \cdot w\right\}
$$

where $0 \leq R A N(0,1) \leq 1$ denote uniformly distributed random numbers. Note that a lower cut-off has been introduced. Further, random noise was added to the data above $10 \mathrm{~cm} \mathrm{~s}^{-1}$,

$$
w \longrightarrow w+R A N(-1,1) \cdot 5 \mathrm{~cm} \mathrm{~s}^{-1}
$$

with $-1 \leq R A N(-1,1) \leq 1$.

The result is shown as the blue distribution in Fig. 3c. While the primary peak region and mean crystal number density are only weakly affected by the added noise, the distribution broadens in the low concentration region and develops a secondary maximum, in better agreement with the observations. The ad-hoc cut-off at $0.2 \mathrm{~cm} \mathrm{~s}^{-1}$ produces a relative maximum in the leftmost bin and prevents nucleation of ice with concentrations below about $\sim 3 \times 10^{-4} \mathrm{~cm}^{-3}$. The mean value of $1 \mathrm{~cm}^{-3}$ is similar to value inferred from the original data. However, the peak region is not well reproduced by the calculation, compare with the observed spectrum given in Fig. 2 (top).
Recall that not all wave signatures that actually caused freezing may be represented by the distributions of $w$ shown in Fig. 1. Thus it is reasonable to account for the action of buoyancy waves at intermediate vertical wind speeds by adding a positive component to $w$ with random amplitudes $0-20 \mathrm{~cm} \mathrm{~s}^{-1}$ in the range $10-80 \mathrm{~cm} \mathrm{~s}^{-1}$

$$
w \longrightarrow w+R A N(0,1) \cdot 20 \mathrm{~cm} \mathrm{~s}^{-1} \text {. }
$$

The net effect of the empirical randomization is to increase the mean value of $w$ by $\sim 5 \mathrm{~cm} \mathrm{~s}^{-1}$. It should be kept in mind that $n_{i}$ is a nonlinear function of $w$, taking the form $n_{i} \propto w^{k}$, with $k=1, \cdots, 3$ (Kärcher and Lohmann, 2002). Averaging over a wave cycle leads to $n_{i}>0$, as ice particles only nucleate when $w$ is positive (in the ascending branch of the wave). This procedure is further motivated by the fact that many mesoscale wave features $(\lambda=10-20 \mathrm{~km})$ were evident in the vertical wind components in cirrus observed during the First International Satellite Cloud Climatology Project Regional Experiment (FIRE) (Gultepe and Starr, 1995). The associated components of $w$ showed amplitudes up to $20 \mathrm{~cm} \mathrm{~s}^{-1}$. The combined effect of added random noise and bias on the distribution of $w$ is further discussed in Sect. 4.

The resulting spectrum (red stair steps) of $n_{i}$ takes into account empirical corrections accounting for noise and waves and is plotted in Fig. 4 (left) along with the observations (histograms). While the broad feature in the low concentration region is only weakly affected by the added biases, the distribution now nicely reproduces the observed primary peak region caused by a redistribution of data points at concentrations above $0.1 \mathrm{~cm}^{-3}$. This implies that the primary concentration peak is associated with the region of updraft speeds around the mean value $27.3 \mathrm{~cm} \mathrm{~s}^{-1}$ of the $w$-distribution. 


\subsection{NH data}

The right column in Fig. 3 and the right panel in Fig. 4 show the results of a similar analysis using the $\mathrm{NH}$ data set.

Aerosol variability. The baseline aerosol parameters listed in Table 1 have been varied within the same ranges as in the SH case; in addition, we varied the nominal heterogeneous freezing threshold of $\mathrm{RHI}_{\mathrm{cr}}=130 \%$ randomly in the range $120-140 \%$. The result is shown in Fig. $3 \mathrm{~d}$ as a green distribution, leading to a value of $1 \mathrm{~cm}^{-3}$ for the predicted mean ice crystal concentration. Another calculation was performed using the homogeneous freezing thresholds, which is shown as the blue distribution with a mean value of $0.5 \mathrm{~cm}^{-3}$.

The spectrum based on heterogeneous freezing is somewhat more variable and predicts about twice as much ice crystals as the homogeneous case. The higher variability is mainly caused by the imposed lower value of the heterogeneous freezing threshold and its random variations. This is expected, as the sensitivity of $n_{i}$ to changes of aerosol parameters increases with decreasing freezing threshold (Kärcher and Lohmann, 2003).

Temperature variability. To produce the green distribution in Fig. 3e, 50,412 ice crystal concentrations have been computed based on the observed temperatures. The spectrum of $n_{i}$ shows some spread in the range $0.6-6 \mathrm{~cm}^{-3}$, with a mean value of $1.1 \mathrm{~cm}^{-3}$. A similar result, shifted towards lower concentrations with a mean of $0.5 \mathrm{~cm}^{-3}$, is obtained when freezing is assumed to occur homogeneously.

Although we carry out calculations assuming that all aerosol particles trigger freezing around $130 \%$, the high ice crystal concentrations observed in the primary peak region in Fig. 3e may in reality have nucleated on both, heterogeneous ice nuclei and liquid supercooled droplets. We recall this issue in Sect. 3.4.

Updraft variability. To produce the green distribution in Fig. 3f, 25,672 ice crystal concentrations have been computed based on the observed updraft speeds. The spectrum of $n_{i}$ is much broader than in the other cases, bracketing the range $3 \times 10^{-3}-100 \mathrm{~cm}^{-3}$, with a mean value of $1.8 \mathrm{~cm}^{-3}$. As in the $\mathrm{SH}$ case, a pronounced peak region develops around $1 \mathrm{~cm}^{-3}$, consistent with the observations (bottom panel in Fig. 2). Adding noise to the data (blue distribution) as described above significantly improves the agreement with the observations, as it was the case with the SH data set.

Finally, Fig. 4 (right panel) depicts the observed spectrum (histogram) along with a calculated distribution (red stair steps) that has been computed with the mean temperature of $226.2 \mathrm{~K}$, with random noise added to the full spectrum of $w$, and with random components added to $w$ to empirically account for wave-induced variability. The resulting distribution is similar to the observed one, but the agreement is not as good as in the SH case. Differences are noticeable both at the lowest and the highest concentrations.

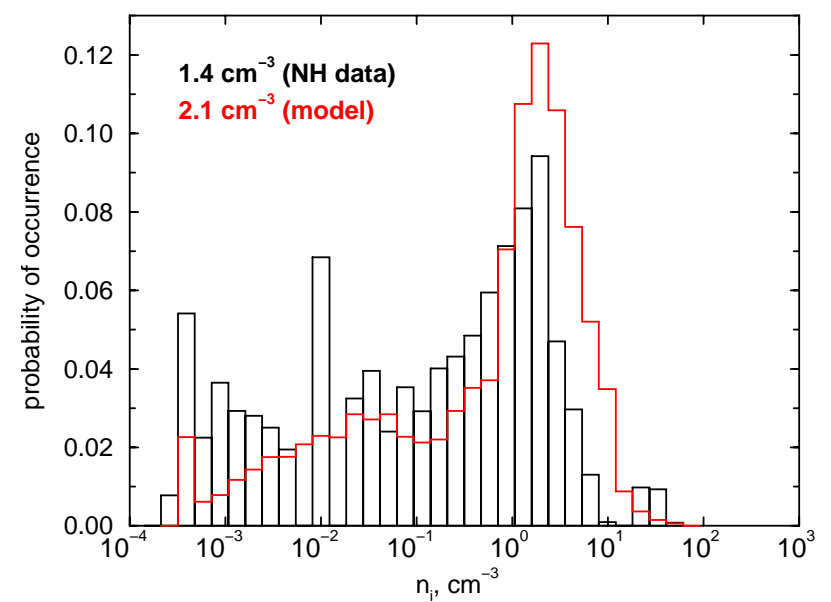

Fig. 5. Same as Fig. 2 (right panel), but using $n_{i}$ and $w$ measurements approximately cleared of convective influence.

\subsection{Sources of uncertainties}

The calculated NH spectrum depicted in Fig. 4 overestimates the location of the peak region and does not show the observed third mode at very high $\left(10-100 \mathrm{~cm}^{-3}\right)$ concentrations (1). The calculated spectra decay more rapidly than the observed spectra at concentrations below $0.1-0.01 \mathrm{~cm}^{-3}$, even with the addition of noise to the vertical wind (2). The following factors left unconsidered above could lead to an improvement.

1. More ice particles are found in the NH data set at very high concentrations as compared to the SH data. However, the few events associated with rapid vertical transport that generate the third peak at concentrations above $20 \mathrm{~cm}^{-3}$ in the NH data set are not explicitly resolved. (Recall the discussion of Figs. 1 and 2 in Sects. 2.1 and 2.3, respectively.) This averages out the actual behavior seen in the observed spectrum. This argument is supported by means of Fig. 5, where we have repeated the calculations that led to Fig. 4 (right panel) using the modified NH data set where most of the high $\mathrm{CO}$ events have been removed. Further, we have used the slightly modified set of aerosol parameters deduced from the reduced data set without high $\mathrm{CO}$ measurements, as given in Table 1.

The agreement between observed and modeled distribution improves, especially in the primary peak region. The remaining differences between both are likely caused by the approximate method to account for waves in our model, which is less accurate in the $\mathrm{NH}$ case as more small-scale variability was evident during the measurements than in the SH case (recall Sect. 2.1). We will study the effects of changes of the vertical velocity spectrum on the distribution of $n_{i}$ further in Sect. 4.2.

In the calculation, the sticking probability $\alpha$ of water vapor moleclues impinging onto the surfaces of growing ice particles (commonly referred to as deposition coefficient) is 


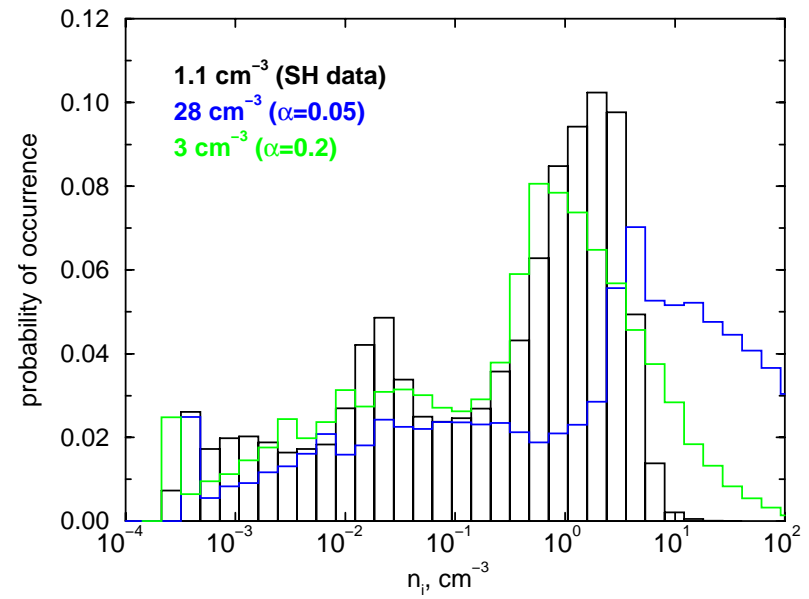

Fig. 6. Observed distribution of $n_{i}$ in the SH (black histogram) taken from Fig. 2 and spectra calculated with a value for the deposition coefficient $\alpha$ of $\mathrm{H}_{2} \mathrm{O}$ molecules on ice lowered by a factor of 10 (blue stair steps) and 2.5 (green stair steps). This calculation does not take into account supercooling and wave-induced variability, which would shift the blue and green distributions to higher concentrations.

set equal to 0.5 . The sensitivity of $n_{i}$ on $\alpha$ is small when $\alpha$ varies in the range $0.1-1$, but increases rapidly below $\alpha=0.1$ (Lin et al., 2002). It has been argued that very low values of the deposition coefficient, $0.001<\alpha<0.1$, could serve as an explanation of the high number densities of ice crystals observed during INCA (Gierens et al., 2003).

To study the effects of small values of $\alpha$ on $n_{i}$, the ice crystal distribution (without supercooling and the effect of waves) has been recalculated with $\alpha=0.05$ (blue stair steps) and $\alpha=0.2$ (green stair steps). The result for $\alpha=0.05$ shown in Fig. 6) is not consistent with the SH data (histogram). The peak region is shifted to the right and is significantly broadened, resulting in a mean value of $28 \mathrm{~cm}^{-3}$. Such high values have not been measured with the CVI; the Forward Scattering Spectrometer Probe (FSSP) detected slightly higher concentrations than the CVI, but not to the extent shown by the blue curve. Values $n_{i}=100 \mathrm{~cm}^{-3}$ are now predicted with high probabilities of 0.03 , but no ice crystals with concentrations above $20 \mathrm{~cm}^{-3}$ have been observed. The low concentration region is shifted to higher values and the secondary peak vanishes, worsening the agreement below $\sim 1 \mathrm{~cm}^{-3}$. For $\alpha=0.2$, the situation improves at low concentrations, but still the model significantly overestimates the high number density portion of the spectrum. Similar results are obtained in the NH case. Hence, exceptionally low values of $\alpha$ are not supported by the field measurements, consistent with previous findings (Haag et al., 2003a).

2 . In constructing the distributions of $n_{i}$, we have assumed that the freezing conditions were met at every $w$ data point (see Sect.3.1). We are confident that this assumption holds for the primary peak region that represents ice crystals formed by homogeneous nucleation; the INCA data set shows that generally, the highest relative humidities measured inside cloud correlate with high ice crystal number densities. In contrast, low ice crystal number concentrations could have been caused by sedimentation, growth/sublimation, and dilution effects affecting already exisiting particles. All of these effects could lead to low ice crystal number densities in cloud layers where freezing is not active.

We think that depositional growth and sublimation have not significantly influenced the INCA data sets taken with the CVI. As outlined in Sect. 2, the measurements were conducted predominantly in the upper cloud part, where sublimation is unlikely to occur. (Even if it occurred, it would not change the number concentration as long as the particles have sizes above the CVI detection limit of $\sim 5 \mu \mathrm{m}$.) According to the observed ice crystal size distributions, the total concentration is controlled by particles smaller than the lower detection limit of the 2D-probe $(\sim 50 \mu \mathrm{m})$. In a typical freezing event, these particles form and initially grow rapidly within tens of seconds (Haag et al., 2003a). Thereafter, the number density stays approximately constant. For this reason, the measured concentrations of such small crystals are equivalent to the nucleated concentrations.

The measurement strategy limited the influence of sedimentation processes, as large ice crystals are mostly absent in upper cloud regions. Although the ice crystal terminal fall speed is a continuous function of the particle size, the vertical profile of ice crystal shapes and sizes from replicator data in a cirrocumulus cloud suggest that particles become large enough (maximum dimension $>50 \mu \mathrm{m}$ ) to render sedimentation especially effective only below $\sim 1 \mathrm{~km}$ below the cloud top (Miloshevich and Heymsfield, 1997). This thickness will depend on details of the vertical profiles of temperature and relative humidity and will differ from cloud to cloud. While we cannot exactly specify the average thickness of the cloud layers probed during the INCA flights, campaign-averaged ice particle size distributions evaluated in different humidity conditions indicate that large crystals with sizes exceeding $50 \mu \mathrm{m}$ contributed less than about $5 \%$ to the total number concentration. In summary, we certainly could not totally avoid probing falling ice crystals, but it is likely that sedimentation affected only a small fraction of the overall total $n_{i}$ data taken during INCA.

Dilution (reduction of number densities of existing ice crystals in dispersing air parcels) may have affected the data set, especially because many measurements were taken at the cloud boundaries. In addition to aerosol effects (discussed next), dilution has the potential to improve the agreement between modeled and measured $n_{i}$ spectra in the low concentration region, but is not easy to consider in the model as dilution rates are not known.

The calculations do not account for the fact that homogeneous and heterogeneous freezing may occur simultaneously. Haag et al. (2003b) and Ström et al. (2003) presented strong 
evidence that this was the case during the $\mathrm{NH}$ measurements by analyzing relative humidity data taken during INCA. In the $\mathrm{NH}$, freezing started at $130 \%$, but the peak humidities measured inside cloud extended to the homogeneous limits, suggesting that ice nuclei contributed to cirrus formation but did not frequently prevent homogeneous freezing from occurring. Kärcher and Lohmann (2003) have emphasized that the competition for available water vapor between ice crystals nucleating from potent ice nuclei and liquid particles will lead to a suppression of $n_{i}$ (negative Twomey effect for cirrus clouds) by up to an order of magnitude in cases where all available ice nuclei are frozen but freezing of liquid particles is not yet initiated. If and how much crystal concentrations are suppressed depends on the temperature, the freezing threshold of ice nuclei, and, most importantly, on the vertical wind speed and number concentrations of ice nuclei relative to the liquid particles. Note that in the presence of waves (i.e., a time sequence of very different cooling rates near the freezing relative humidity), it is not easy to assess the effectiveness of this indirect aerosol effect on $n_{i}$; this issue should be investigated further in future work.

In summary, it is conceivable that the inclusion of dilution and sedimentation effects and a refined formulation for heterogeneous freezing in the calculation would improve the agreement with the $\mathrm{NH}$ observations by further broadening the low concentration part of the spectrum and, at the same time, by shifting the peak region more to the left. A better understanding of these processes prevalent during INCA is required before this conjecture can be tested.

\section{Discussion and Summary}

We have demonstrated that the variability of vertical air motion alone can explain the key features of observed distribution of $n_{i}$, emphasizing the important role of cloud-scale buoyancy waves. While synoptic-scale updrafts affect the low concentration regime $\left(<0.1 \mathrm{~cm}^{-3}\right)$, mesoscale variability explains the occurrence of the peak region at intermediate concentrations $\left(0.1-10 \mathrm{~cm}^{-3}\right)$, and convection may cause another maximum in the high concentration regime $\left(>10 \mathrm{~cm}^{-3}\right)$. Mesoscale waves, however, can also contribute to the low and high concentration regions, depending on the exact phase of the waves at and above the freezing threshold (Lin et al., 1998). Below we study the impact of changed dynamical forcing and aerosol properties on the distribution of $n_{i}$ and the vertical motion variability as computed by large-scale models. Before we tackle these issues, we make an attempt to quantify the small-scale temperature fluctuations of the underlying vertical wind measurements.

\subsection{Mesoscale temperature fluctuations}

A good agreement between modeled and measured spectra of $n_{i}$ was obtained after perturbing the Falcon vertical wind

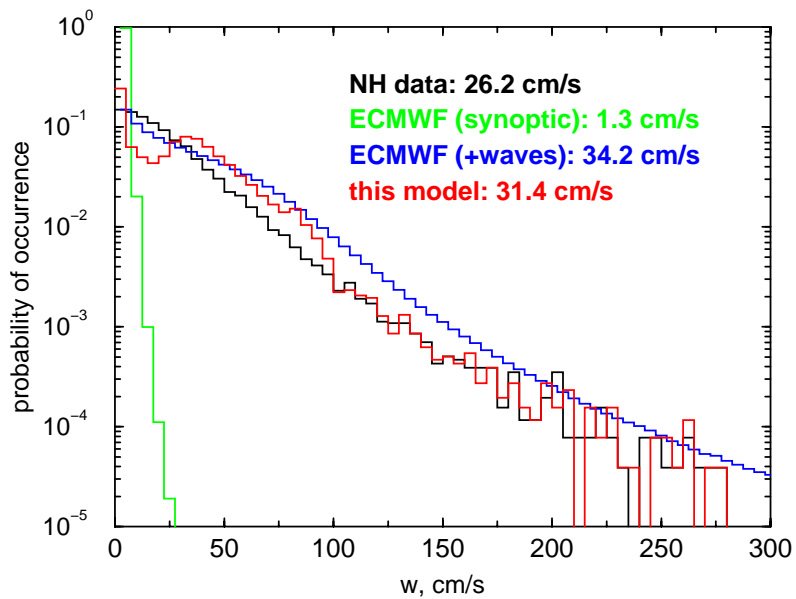

Fig. 7. Distributions of updraft speeds (left panel) from the NH data set (black), from the randomized NH data set with noise and wavedriven variability added as described in Sect. 3.2 (red), from trajectories calculated using ECMWF synoptic wind fields (green), and from the same ECMWF data with superimposed small-scale temperature fluctuations (blue). Mean values of $w$ are indicated. See text for details.

data with noise and wave-induced variability. Here, we discuss how this perturbed distribution of $w$ looks like and how it compares with a wind speed spectrum obtained from trajectory simulations.

Figure 7 shows several distributions of $w$. The black distribution repeats the measured $\mathrm{NH}$ data from INCA. The green distribution (labelled "synoptic") was obtained from the European Centre for Medium-Range Weather Forecasts (ECMWF) global model based on operational vertical wind fields (within $150-350 \mathrm{hPa}$ ) with $\sim 40 \mathrm{~km}$ horizontal resolution; smaller-scale gravity waves, non-hydrostatic waves, and deep convection are not explicitly resolved. Trajectories have been calculated from the three-dimensional wind fields and the cooling rates have been transformed into updraft speeds by assuming adiabatic motion. The resulting mean updraft speed of $1.3 \mathrm{~cm} \mathrm{~s}^{-1}$ is dramatically smaller than the measured value.

The red distribution is equivalent to the measured one but includes random noise and wave-induced variability as explained in Sect.3.2. The ad-hoc procedure to account for these effects raises the mean updraft speed by $5.2 \mathrm{~cm} \mathrm{~s}^{-1}$, altering the distribution mainly below $100 \mathrm{~cm} \mathrm{~s}^{-1}$. To calculate the blue distribution (labelled "waves"), we have used the synoptic-scale ECMWF trajectories and superimposed small-scale temperature fluctuations. The fluctuations consist of a random sequence of sine waves with changing amplitudes $\Delta T$ and periods $\tau$. The wave characteristics have been varied such that the resulting distribution of updraft speeds provides a good fit to the INCA data.

Specifically, we have used a uniform distribution of $\Delta T$ in the range $0-2 \mathrm{~K}$ and a normally distributed range of $\tau$ with a 

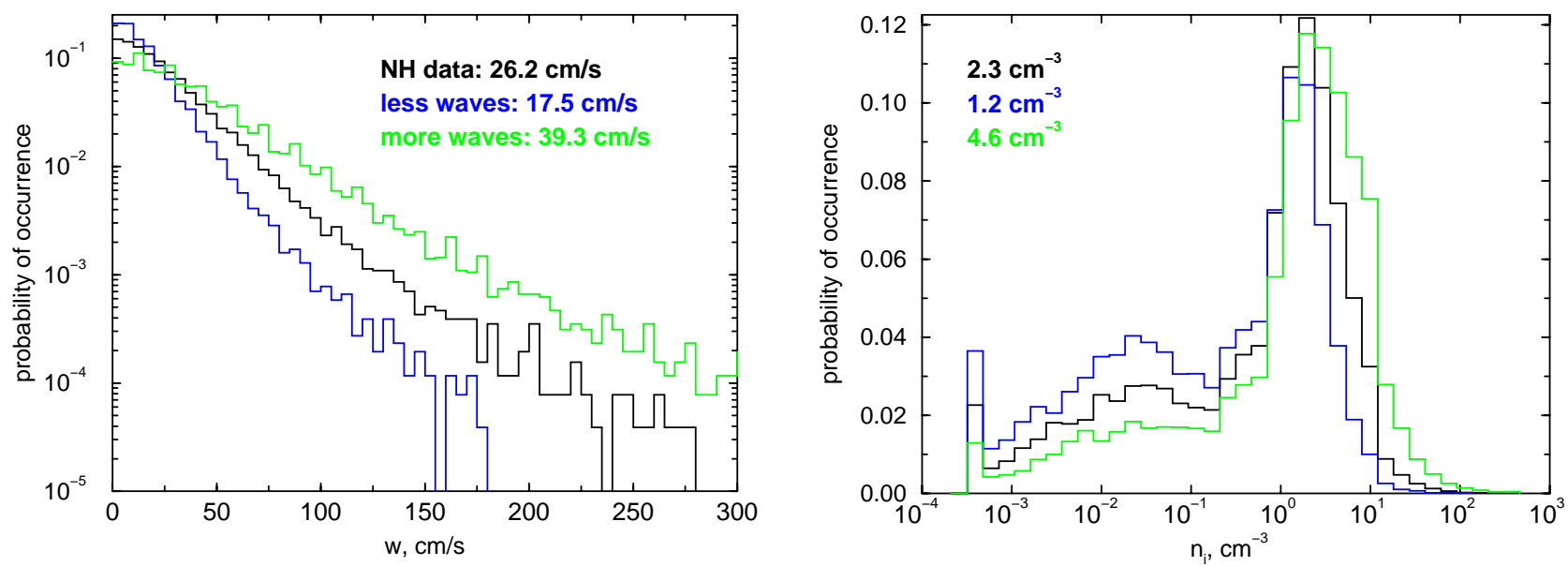

Fig. 8. Distributions of updraft speeds (left panel) from the NH data set (black), and from modified NH data sets with more wave activity (green) and less wave activity (blue); the original NH updraft speeds have been multiplied and divided by a factor of 1.5 , respectively. The distributions of $n_{i}$ obtained from calculations are shown in the right panel. Noise and wave-driven variability was added to all updraft speeds (not shown) to calculate the distributions of $n_{i}$.

mean value of $1200 \mathrm{~s}$ and a standard deviation of $400 \mathrm{~s}$. In reality, higher frequency waves tend to have smaller amplitudes and vice versa. Besides this point, this choice of wave parameters is not inconsistent with what is currently known about small-scale temperature fluctuations arising from mesoscale gravity waves (see Gary (2002) for more information). As a result, we observe in Fig. 7 that the blue distribution can be regarded as an average between the red and black distributions, supporting the approach used in Sect. 3.2.

The region above $100 \mathrm{~cm} \mathrm{~s}^{-1}$ contributes only little to the distributions of $n_{i}$. The region near the mean value $30-35 \mathrm{~cm} \mathrm{~s}^{-1}$ controls the primary peak region of the $n_{i}$ spectra. Updraft speeds below $10 \mathrm{~cm} \mathrm{~s}^{-1}$ are underrepresented in the blue distribution, as we have not considered longer wave periods which are actually present in the atmosphere.

Implicit in our calculations of total $n_{i}$ is the assumption that the nucleating air parcels follow the wave-like motions for the scale of vertical displacement necessary to reach the freezing thresholds. This issue is tied to the amplitudes of the temperature oscillations caused by the waves, and cannot be examined quantitatively without comprehensive cirrus models or a detailed analysis of the spectral wave properties. This calls attention to the need of measuring and anaylzing smallscale temperature fluctuations accurately over a wide range of wavelengths in future cirrus campaigns.

\subsection{Dynamical variability}

How does the spectrum of ice crystal concentration changes when the spectrum of vertical winds changes in a future climate? It is not known how vertical motions will change in the future. Even for the current atmosphere, a global clima- tology of vertical air motion is not available. However, we may estimate potential changes of the distribution of $n_{i}$ by prescribing different vertical wind distributions in our model.

Figure 8 (top panel) depicts the $\mathrm{NH}$ vertical wind distribution already discussed in Sect. 2.1 as black stair steps. The blue distribution (labeled "less waves") results from dividing these values by 1.5. The frequency of occurrence of velocities $>30 \mathrm{~cm} \mathrm{~s}^{-1}$ is reduced, while lower winds speeds are more likely to occur. The green distribution (labeled "more waves") is obtained by multiplying each value of $w$ of the black distribution by 1.5. Here, the frequency of occurrence of velocities $>30 \mathrm{~cm} \mathrm{~s}^{-1}$ is enhanced while lower winds speeds occur with reduced probability.

Figure 8 (bottom panel) depicts the resulting distributions of $n_{i}$, using the same color code. These calculations consider the addition of noise and wave-driven variability to the original vertical velocities, as described in Sect.3. Compared to the baseline case (mean $n_{i}$ value of $2.3 \mathrm{~cm}^{-3}$ from the model), the mean concentrations vary by factors $0.5-2$ when the wave-driven forcing is reduced or enhanced by a factor of 1.5. We note that a decrease of the average air temperature by $3 \mathrm{~K}$ would lead to roughly comparable changes of the distribution of $n_{i}$ (compare with Fig. 3b). In particular, from Fig. 8 we infer that the probability to find concentrations of $\sim 0.05 \mathrm{~cm}^{-3}$ nearly doubles and the probability to find values of $10 \mathrm{~cm}^{-3}$ rises almost by a factor of 8 .

Summary. At midlatitudes during INCA, the spectrum of $w$ was largely governed by mesoscale variability, with sufficient potential to preferentially activate the homogeneous freezing mode. Enhancing or suppressing this variability may significantly alter the distribution of ice crystal concentrations in young cirrus clouds. As gravity waves appear to be widespread also in other atmospheric regions, 

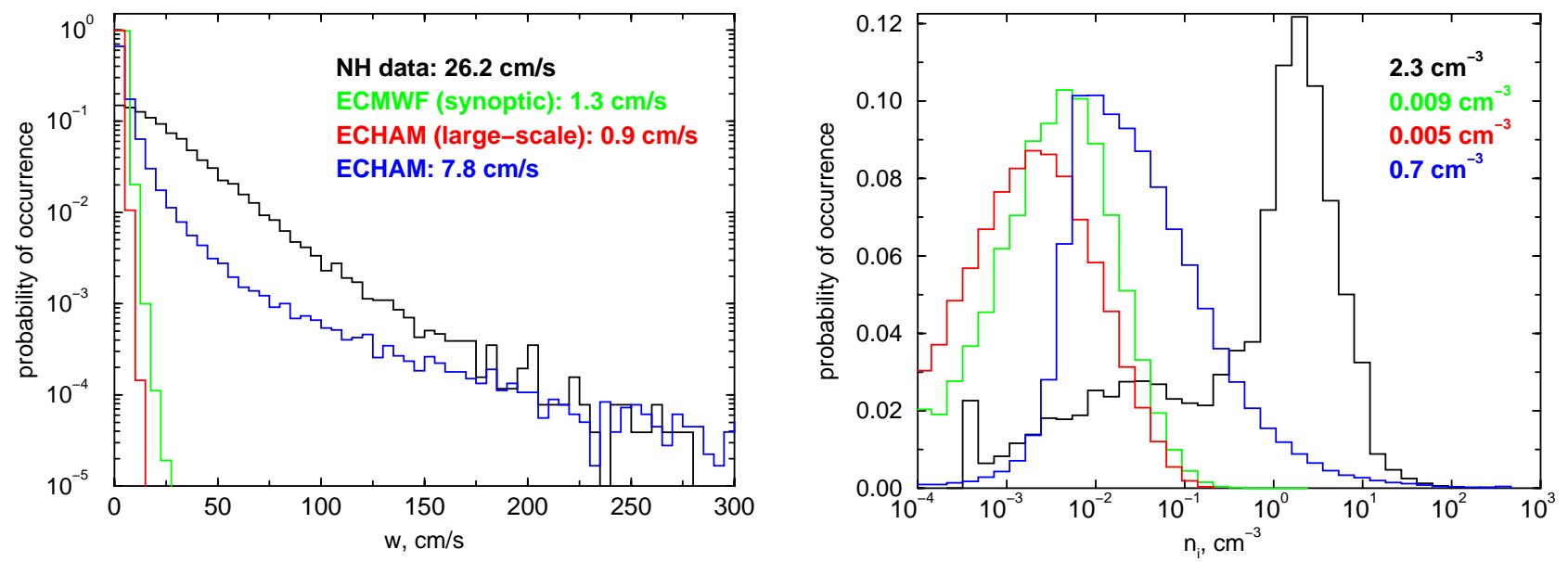

Fig. 9. Distributions of updraft speeds (left panel) from the NH data set (black), from upper tropospheric synoptic-scale winds caluclated by the ECMWF weather forecast model (green), from upper tropospheric large-scale winds caluclated by the ECHAM general circulation model (red), and from corresponding ECHAM simulations where a subgrid-scale component was added to the large-scale vertical wind (Lohmann and Kärcher, 2002) (blue). The distributions of $n_{i}$ obtained from calculations are shown in the right panel. No additional artificial noise or wave-driven variability was added to calculate the distributions of $n_{i}$.

such as the tropical upper troposphere and tropopause region (Karoly et al., 1996) or the Arctic polar lower stratosphere (Dörnbrack and Leutbecher, 2001), it is highly likely that our findings also apply to other cases, including tropical cirrus and polar stratospheric clouds. Our results clearly call for the need to better understand the sources and characteristics of gravity waves near the tropopause as a prerequisite to study their impact on cirrus formation in more detail.

\subsection{Vertical motion variability in large-scale models}

It is interesting to delineate implications of our results for simulations of cirrus clouds with large-scale atmospheric models. Specifically, we describe the upper tropospheric vertical wind fields taken from the ECMWF global model (described in Sect. 4.1) and the ECMWF-model Hamburg version (ECHAM), and discuss resulting probability distributions of $n_{i}$ obtained with our approach. Noise and waveinduced variability is not added to the global wind fields.

The first set of global calculations was based on the operational ECMWF synoptic wind fields. To date, cirrus clouds are not simulated interactively in the ECMWF forecast system, as in most other global models. The second set of global model results was based on ECHAM largescale wind fields (within $175-275 \mathrm{hPa}$ ) with $\sim 300 \mathrm{~km}$ horizontal resolution; again, smaller-scale dynamical forcings are not explicitly resolved. However, in another set of ECHAM wind fields, a component proportional to the turbulent kinetic energy is added to the large-scale mean value of the vertical velocity to approximately account for subgridscale variability in vertical air motion. The latter wind fields have been employed to simulate cirrus clouds interactively in ECHAM (Lohmann and Kärcher, 2002). More details of the ECMWF and ECHAM simulations are discussed in Haag et al. (2003b).

Can current large-scale models reliably predict cirrus cloud properties? The answer is no, because such models do not consider the subgrid-scale variability of vertical air motion in the calculation of cirrus cloud properties. Figure 9 (left) shows the green distribution of $w$ from the ECMWF model, repeated from Fig. 7. Given the steep decrease of the distribution as compared to the cloud-scale observations and the low mean vertical velocity of $1.3 \mathrm{~cm} \mathrm{~s}^{-1}$, the synopticscale updrafts result in an ice crystal concentration spectrum and a mean $n_{i}$ value in striking disagreement with both, the observations and our model, see Fig. 9 (right).

Figure 9 (left) shows the ECHAM results using the largescale winds only (red) and with the mesoscale components added to the large-scale winds (blue). The ice crystal distribution based on large-scale winds is worse than the ECMWF result (red distribution in the right panel), as the mean large-scale vertical velocity from ECHAM is smaller than the ECMWF mean. This is mainly caused by the much coarser horizontal and vertical resolution of the ECHAM model.

However, the ECHAM results improve when empirical subgrid-scale components (scaling with the model's turbulent kinetic energy) are added to the large-scale vertical winds (blue distributions in Fig.9). The distribution of $w$ now extends into the convective regime, but still severly underestimates the intermediate mesoscale regime and overemphasizes the lowest wind speeds. Compared with the largescale only case (red distributions), the ice crystal distribution is shifted towards higher concentrations. While this approach leads to quite realistic distributions of relative humidity in ice-supersaturated regions (Haag et al., 2003b), the 
vertical velocity does not exhibit the same fine scale structure as indicated by observations and is therefore unable to reproduce distributions of $n_{i}$ as those measured during INCA (Lohmann et al, 2003).

In judging about the present ECHAM results including the subgrid-scale updraft component, we note that the simulated ice crystal concentrations represent mean values averaged over a model grid box. These averages cannot be directly compared to the observations (or, equivalently, to our model results); the same holds for the ECMWF results. However, taken as grid box means, the mean number density of $0.7 \mathrm{~cm}^{-3}$ predicted by ECHAM is a reasonable value.

Summary. It is highly desirable to develop a prognostic parameterization for the subgrid-scale variability of vertical air motion caused by waves on the mesoscale. Such a parameterization, ideally combined with prognostic schemes for the ice cloud number density (Wilson and Ballard, 1999; Lohmann and Kärcher, 2002) and perhaps fractional cirrus cover in the spirit of Tompkins (2002), could be coupled to the parameterization of cirrus cloud formation developed recently (Kärcher and Lohmann, 2002, 2003).

\subsection{Indirect aerosol effect on cirrus}

At the end of Sect. 2.3, we saw the possibility emerging that details of the freezing processes have little impact on certain cirrus cloud properties. The subsequent analysis provided further evidence for a limited indirect aerosol effect on the distribution of ice crystals in young cirrus clouds, because the general shape of the distributions of $n_{i}$ is strongly controlled by the distribution of vertical velocities.

To gain additional insight, we have used the average $\mathrm{SH}$ aerosol parameters (including the freezing threshold) in conjunction with $\mathrm{NH}$ vertical winds and vice versa to calculate distributions of $n_{i}$. The results are shown in Fig. 10, where the best estimate model results (repeated from Fig. 4 and now plotted as black stair steps) are contrasted with the results obtained by exchanging the interhemispheric aerosol size distribution and freezing properties (plotted as blue distributions) for the NH (top panel) and the SH (bottom panel).

It is interesting to note that the general shape of the curves does not depend on the assumption whether freezing occurs purely homogeneously or purely heterogeneously. The mean value of $n_{i}$ roughly varies within a factor of two between both cases. Keeping the cloud ice water content fixed, halving or doubling $n_{i}$ (as induced by the aerosol changes) will increase or decrease the mean number diameter of the ice crystals by a factor of $2^{1 / 3}=1.26$.

The aerosol-induced changes in the distributions of $n_{i}$ between each of the two scenarios are mainly caused by the different freezing thresholds $(\sim 130 \%$ versus $\sim 155 \%$, compare Figs. $3 \mathrm{~d}$ and $3 \mathrm{e}$ ). In the primary peak region, they are comparable to those induced by the perturbed vertical winds as shown in Fig. 8 and are less dramatic in the region around the secondary peak. However, as noted above, inclusion of
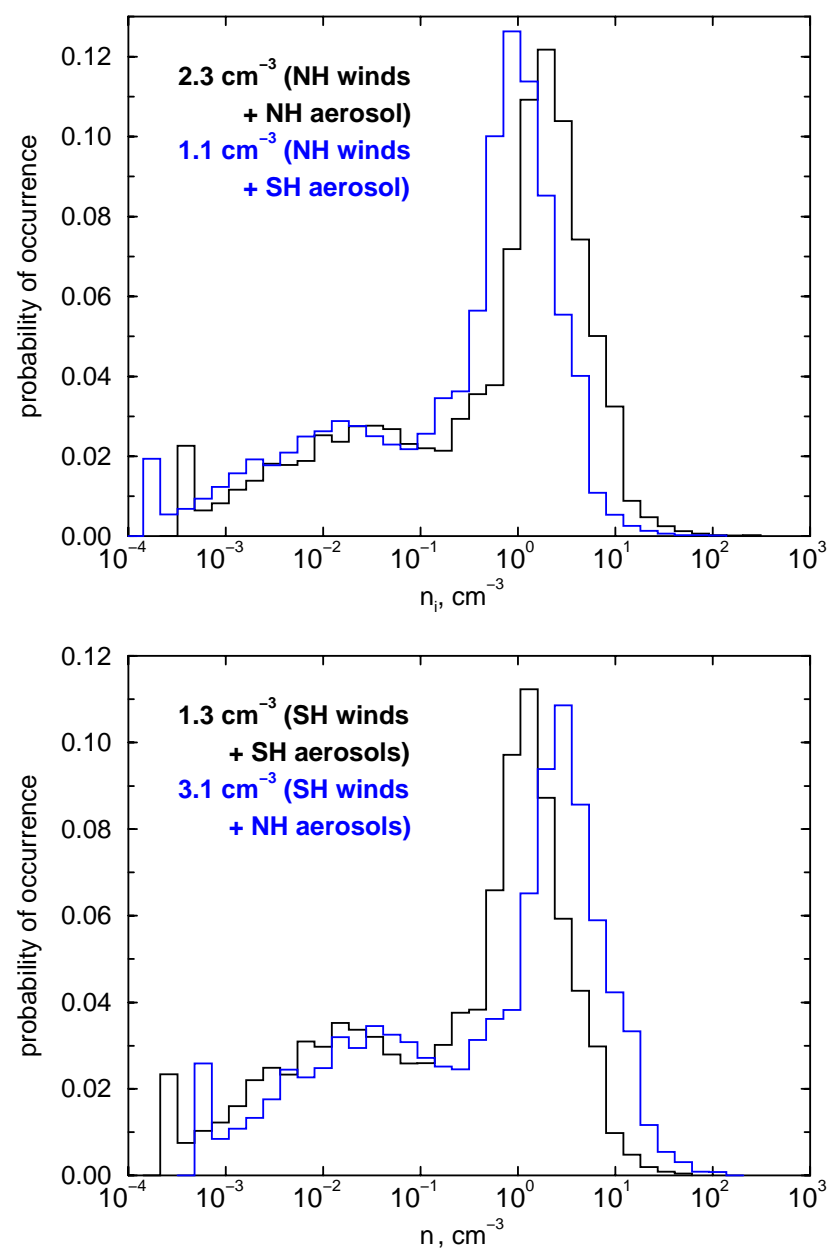

Fig. 10. Calculated distribution functions of ice particle number densities using the $\mathrm{NH}$ wind data (top panel) and the $\mathrm{SH}$ wind data (bottom panel). The black distributions use the respective aerosol parameters given in Table 1 and are repeated from Fig. 4 (shown there in red). The blue distributions use exchanged aerosol parameters. Mean values of $n_{i}$ are indicated.

competition between different types of freezing nuclei may more strongly modify the low concentration part of the $n_{i}$ distribution.

Our findings are useful in outlining two potential consequences of aerosol-induced cirrus modifications.

First, it is possible that ice nuclei exert a substantial influence on the properties of optically thin (subvisible) cirrus clouds with low ice crystal number densities generated in weak updrafts (Kärcher, 2002). The impact of heterogeneous freezing diminishes with increasing updraft speed (or increasing $n_{i}$ ), because the number of efficient ice nuclei present in the upper troposphere will be limited and will stay below the total number of available aerosol particles. In optically thicker cirrus clouds, ice nuclei will create the first ice crystals which grow to the largest sizes. These crystals will preferentially sediment to lower altitudes. The associated 
vertical redistribution of ice water mass and ice nuclei may lead to enhanced dehydration of upper cloud levels near the tropopause and to enhanced seeding of ice in mixed phase clouds at lower levels.

Second, the spatial extent and frequency of occurrence of cirrus may increase with decreasing freezing thresholds $\mathrm{RHI}_{\mathrm{cr}}$, as the atmosphere contains more weakly ice supersaturated regions than regions with high supersaturations near the homogeneous limit. How much the areal ratio between highly and more weakly supersaturated regions changes depends on details of the atmospheric dynamics (Haag et al., 2003b) and is difficult to predict. On the other hand, even moderate changes in the dynamical forcing may likewise affect the spatial and temporal cirrus coverage. Hence, it may be difficult to separate the effects of aerosol changes and dynamical changes on the cloud cover.

Summary. As we neither know how upper tropospheric abundances of ice nuclei nor how vertical wind and temperature fields will change in a future climate, it is difficult to estimate the relative importance of the indirect aerosol effect and changes in the dynamical forcing patterns on cirrus clouds. In any case, we reiterate that homogeneous freezing alone would largely be consistent with the CVI measurements, provided the dynamical forcing is adequately taken into account. (Pure heterogeneous freezing is not consistent with the in-cloud measurements of relative humidity, see Haag et al. (2003b).) We have shown that cirrus formation is at least as, and probably more, sensitive to changes in dynamical forcing patterns as to changes in the aerosol size and number. More significant changes may occur when mixtures of liquid particles and efficient ice nuclei are present. This could lead to a partial redistribution of ice crystal concentrations, not to a substantial change of the distribution functions of $n_{i}$; however, we did not yet achieve sufficient understanding of the actual freezing mechanisms in cirrus clouds to reach a definite conclusion.

The consequences of these proposed modifications for the cloud life cycle are not clear at this point and need to be assessed in future work. Differencing between natural and anthropogenic causes of possible cirrus cloud changes in a future climate or trends in cirrus cloud cover will require a very careful and detailed analysis of underlying processes.

\section{Conclusions}

The conclusions of this study are as follows:

1. The general shape of the distribution of total ice crystal concentrations in young cirrus clouds observed at midlatitudes during INCA consists of a predominant primary peak at concentrations $0.1-10 \mathrm{~cm}^{-3}$, and a less pronounced, secondary peak at $\sim 0.02 \mathrm{~cm}^{-3} \mathrm{em}-$ bedded in a broad feature extending to concentrations of $\sim 3 \times 10^{-4} \mathrm{~cm}^{-3}$. Another peak at concentrations
$10-100 \mathrm{~cm} \mathrm{~s}^{-1}$ appeared in NH measurements, but not in the SH data set.

2. Mesoscale variability in updraft velocities in combination with pure homogeneous freezing processes accounts for most of the observed variance in the total number densities of ice crystals. Mean ice particle concentrations may decrease when efficient ice nuclei compete with liquid particles during cirrus cloud formation. Number densities of upper tropospheric ice nuclei are possibly too low to account for a substantial fraction of ice crystals observed in the primary peak region.

3. Mesoscale variability in vertical velocities in the range $10-100 \mathrm{~cm} \mathrm{~s}^{-1}$ caused by small-scale temperature fluctuations accounts for much of the observed high number densities $\left(0.1-10 \mathrm{~cm}^{-3}\right)$ of homogeneously formed ice crystals in young cirrus. This ice particle mode controls the effective ice crystal radius and hence important radiative cirrus cloud properties. Strong convective forcing can produce even higher ice particle concentrations. The impact of heterogeneous freezing processes in these concentration regions is minimal.

4. Large-scale or wave-driven variations in vertical velocities below $10 \mathrm{~cm} \mathrm{~s}^{-1}$ contribute to the observed low number densities $\left(<0.1 \mathrm{~cm}^{-3}\right)$ of ice crystals in young cirrus by activating efficient ice nuclei in the absence of homogeneous freezing. The impact of heterogeneous freezing processes in this concentration region is potentially large. An assessment of this impact is difficult, as sedimentation and dispersion of air parcels containing already exisiting ice crystals could have also caused the low concentrations in the data sets.

5. It is difficult to assess the relative importance of the indirect aerosol effect and changes in the dynamical forcing patterns on cirrus clouds in a future climate. Both factors could alter cirrus cloud properties by similar amounts, but the current knowledge about mesoscale temperature fluctuations induced by ubiquitous gravity waves and freezing mechanisms in cirrus clouds is very limited and prevents definite conclusions to be drawn. In any case, buoyancy waves inducing mean updraft speeds of $\sim 30 \mathrm{~cm} \mathrm{~s}^{-1}$ or higher tend to minimize the impact of ice nuclei on the total ice crystal number density.

6. There is an urgent need to characterize small-scale temperature fluctuations accurately over a wide range of wavelengths in future cirrus campaigns as well as to improve the representation of such vertical air motions in large-scale models. Improving the representation of subgrid-scale variability in updraft speeds, or cooling rates, in atmospheric models is an essential prerequisite to predicting cirrus clouds globally and to study their role in climate change scenarios. 
Acknowledgements. We are grateful to Robert Baumann, Werner Haag, and Andreas Minikin for help with the INCA data base, and to Ulrike Lohmann for contributing the ECHAMN simulations. Thanks also go to Andreas Dörnbrack and David Fahey for helpful discussions. This research was conducted within the projects "Particles in the Upper Troposphere and Lower Stratosphere and Their Role in the Climate System" (PARTS) and "Interhemispheric Differences in Cirrus Properties From Anthropogenic Emissions" (INCA), both funded by the European Commission. It contributes to the project "Particles and Cirrus Clouds" (PAZI) supported by the Helmholtz-Gemeinschaft Deutscher Forschungszentren (HGF). One of us (BK) acknowledges the hospitality of the staff at the Meteorological Institute at Stockholm University (MISU) during a scientific stay and thanks Kevin Noone and Douglas Nilsson for stimulating discussions.

\section{References}

Baehr, J., Schlager, H., Ziereis, H., Stock, P., van Velthoven, P., Busen, R., Ström, J., and Schumann, U.: Aircraft observations of $\mathrm{NO}, \mathrm{NO}_{\mathrm{y}}, \mathrm{CO}$ and $\mathrm{O}_{3}$ in the middle and upper troposphere from $60^{\circ} \mathrm{N}$ to $60^{\circ} \mathrm{S}$ - Interhemispheric differences at midlatitudes, Geophys. Res. Lett., in press, 2003.

Bögel, W. and Baumann, R.: Test and calibration of the DLR Falcon wind measuring system by maneuvers, J. Atmos. Oceanic Technol., 8, 5-18, 1991 .

Boucher, O.: Influence of air traffic on cirrus occurrence, Nature, 397, 30-31, 1999.

Carslaw, K. S., Wirth, M., Tsias, A., Luo, B. P., Dörnbrack, A., Leutbecher, M., Volkert, H., Renger, W., Bacmeister, J. T., Reimer, E., and Peter, Th.: Increased stratospheric ozone depletion due to mountain-induced atmospheric waves, Nature, 391, 675-678, 1998.

Dörnbrack, A. and Leutbecher, M.: Relevance of mountain waves for the formation of polar stratospheric clouds over Scandinavia: A 20 year climatology, J. Geophys. Res., 106, 1583-1593, 2001.

Gary, B.: Mesoscale temperature fluctuations: An overview, http: //reductionism.net.seanic.net/bgary.mtp2/isentrop/index.html, 2002.

Gayet, J.-F., Auriol, F., Minikin, A., Ström, J., Seifert, M., Krejci, R., Petzold, A., Febvre, G., and Schumann, U.: Quantitative measurement of the microphysical and optical properties of cirrus clouds with four different in-situ probes: Evidence of small ice crystals, Geophys. Res. Lett., 29, 24, 2230, doi:10.1029/2001GL014342, 2002.

Gierens, K., Monier, M., and Gayet, J.-F.: The deposition coefficient and its role for cirrus clouds, J. Geophys. Res., 108, 4069, doi:10.1029/2001JD001558, 2003.

Gultepe, I. and Starr, D. O'C.: Dynamical structure and turbulence in cirrus clouds: Aircraft observations during FIRE, J. Atmos. Sci., 52, 4159-4182, 1995.

Haag, W., Kärcher, B., Schaefers, S., Stetzer, O., Möhler, O., Schurath, U., Krämer, M., and Schiller, C.: Numerical simulations of homogeneous freezing processes in the aerosol chamber AIDA, Atmos. Chem. Phys., 3, 195-210, 2003a.

Haag, W., Kärcher, B., Ström, J., Minikin, A., Lohmann, U., Ovarlez, J., and Stohl, A.: Freezing thresholds and cirrus cloud formation mechanisms inferred from in situ measurements of relative humidity, Atmos. Chem. Phys. Discuss., 3, accepted, 2003b.
Heymsfield, A. J.: Precipitation development in stratiform ice clouds: A microphysical and dynamical study, J. Atmos. Sci., 34, 367-381, 1977.

Heymsfield, A. J. and Miloshevich, L. M.: Homogeneous ice nucleation and supercooled liquid water in orographic wave clouds, J. Atmos. Sci., 50, 2335-2353, 1993.

Intergovernmental Panel on Climate Change (IPCC): Aviation and the Global Atmosphere, Special Report,Cambridge Univ. Press, New York, 65-120, 1999.

Jensen, E. J., Toon, O. B., Westphal, D. L., Kinne, S., and Heymsfield, A. J.: Microphysical modeling of cirrus, 2. Sensitivity studies, J. Geophys. Res., 99, 10 443-10 454, 1994.

Jensen, E. J. and Toon, O. B.: The potential importance of soot particles from aircraft exhaust on cirrus clouds, Geophys. Res. Lett., 24, 249-252, 1997.

Kärcher, B.: Properties of subvisible cirrus clouds formed by homogeneous freezing, Atmos. Chem. Phys., 2, 161-170, 2002.

Kärcher, B. and Lohmann, U.: A parameterization of cirrus cloud formation: Homogeneous freezing including effects of aerosol size, J. Geophys. Res., 107, 4698, doi:10.1029/2001JD001429, 2002.

Kärcher, B. and Lohmann, U.: A parameterization of cirrus cloud formation: Heterogeneous freezing, J. Geophys. Res., 108, doi:10.1029/2002JD003220, in press, 2003.

Karoly, D. J., Rolf, G. L., and Reeder, M. J.: Gravity wave activity associated with tropical convection detected in TOGA-COARE sounding data, Geophys. Res. Lett., 23, 261-264, 1996.

Koop, Th., Luo, B. P., Tsias, A., and Peter, Th.: Water activity as the determinant for homogeneous ice nucleation in aqueous solutions, Nature, 406, 611-614, 2000.

Lin, H., Noone, K. J., Ström, J., and Heymsfield, A. J.: Dynamical influences on cirrus cloud formation processes, J. Atmos. Sci., 55, 1940-1949, 1998.

Lin, R.-F., Starr D. O’C., DeMott, P. J., Cotton, R., Sassen, K., Jensen, E., Kärcher, B., and Liu, X.: Cirrus parcel model comparison project phase 1: The critical components to simulate cirrus initiation explicity, J. Atmos. Sci., 59, 2305-2329, 2002.

Lohmann, U., and Kärcher, B.: First interactive simulations of cirrus clouds formed by homogeneous freezing in the ECHAM GCM, J. Geophys. Res., 107, 4105, doi:10.1029/2001JD000767, 2002.

Lohmann, U., Kärcher, B., and Timmreck, C.: Impact of the Mt. Pinatubo eruption on cirrus clouds formed by homogeneous freezing in the ECHAM GCM, J. Geophys. Res., 108, doi:10.1029/2002JD003185, in press, 2003.

Miloshevich, L. M. and Heymsfield, A. J.: A balloon-borne continuous cloud particle replicator for measuring vertical profiles of cloud microphysical properties: Instrument design, performance, and collection efficiency analysis, J. Atmos. Oceanic Technol., 14, 753-768, 1997.

Minikin, A., Petzold, A., Ström, J., Krejci, R., Seifert, M., van Velthoven, P., Schlager, H., and Schumann, U.: Aircraft observations of the upper tropospheric fine particle aerosol in the northern and southern hemispheres at midlatitudes, Geophys. Res. Lett., 30, doi:10.1029/2002GL016458, in press, 2003.

Noone, K., Ogren, J. A., Heintzenberg, J., Charlson, R. J., and Covert, D. S.: Design and calibration of a counterflow virtual impactor for sampling of atmospheric fog and cloud droplets, Aerosol Sci. Technol., 8, 235-244, 1988. 
Ovarlez, J., Gayet, J.-F., Gierens, K., Ström, J., Ovarlez, H., Auriol, F., Busen, R., and Schumann, U.: Water vapour measurements inside cirrus clouds in Northern and Southern hemispheres during INCA, Geophys. Res. Lett., 29, 1813, doi:10.1029/2001GL014440, 2002.

Quante, M. and Starr, D. O'C.: Dynamical processes in cirrus clouds, in: Cirrus, Lynch, D.K., Sassen, K., Starr, D.O'C., Stevens, G. (Eds.), Oxford Univ. Press, New York, 346-374, 2002.

Seifert, M., Ström, J., Krejci, R., Minikin, A., Petzold, A., Gayet, J.F., Schumann, U., and Ovarlez, J.: In-situ observations of aerosol particles remaining from evaporated cirrus crystals: Comparing clean and polluted cases, Atmos. Chem. Phys. Discuss., 2, 15991633, 2002.

Starr, D. O'C. and Cox, S. K.: Cirrus clouds, Part II: Numerical experiments on the formation and maintenance of cirrus, J. Atmos. Sci., 42, 2682-2694, 1985.

Stephens, G. L., Tsay, S. C., Stackhouse, P. W., and Flatau, P. J.: The relevance of the microphysical and radiative properties of cirrus clouds to climate and climatic feedback, J. Atmos. Sci., 47, 1742-1753, 1990.
Ström, J., Strauss, B., Anderson, T., Schröder, F., Heintzenberg, J., and Wendling, P.: In situ observations of the microphysical properties of young cirrus clouds, J. Atmos. Sci., 54, 2542-2553, 1997.

Ström, J., Seifert, M., Kärcher, B., Minikin, A., Gayet, J.-F., Krejci, R., Petzold, A., Auriol, F., Busen, R., Schumann, U., Haag, W., Hansson, H.-C.: Cirrus cloud occurrence as a function of ambient relative humidity: A comparison of observations from the Southern and Northern hemisphere midlatitudes obtained during the INCA experiment, Atmos. Chem. Phys. Discuss., 3, accepted, 2003.

Tompkins, A.: A prognostic parameterization for the subgrid-scale variability of water vapor and clouds in large-scale models and its use to diagnose cloud cover, J. Atmos. Sci., 59, 1917-1942, 2002.

Wilson, D. R. and Ballard, S. P.: A microphysically based precipitation scheme for the UK Meteorological Office Unified Model, Q. J. R. Meteorol. Soc., 125, 1607-1636, 1999.

Zhang, Y., Laube, M., and Raschke, E.: Evolution of stratiform cirrus simulated in a lifting layer, Contr. Atmos. Phys., 65, 2334, 1992. 